\title{
Delayed presentation of a patient with a ruptured diaphragm complicated by gastric incarceration and perforation after apparently minor blunt trauma
}

\author{
Brian K.P. Goh, MB BS, MRCS; Andrew S.Y. Wong, MB BS, FRCS; Khoon-Hean Tay, MB BS, FRCS; \\ Michael N.Y. Hoe, MB BS, FRCS
}

\begin{abstract}
Rupture of the diaphragm is almost always due to major trauma and is most commonly associated with road-traffic accidents. We report a case of delayed presentation of a 35-year-old woman with a ruptured diaphragm, 11 days following apparent minor blunt trauma. This case illustrates how the diagnosis of ruptured diaphragm can be missed and demonstrates the importance of considering this diagnosis in all cases of blunt trauma to the trunk. It also demonstrates the potential pitfall of misinterpreting the chest radiograph, and the value of repeat imaging after insertion of a nasogastric tube.
\end{abstract}

Key words: delayed presentation; ruptured diaphragm; minor blunt trauma; gastric incarceration; gastric perforation

\begin{abstract}
RÉSUMÉ
La rupture du diaphragme est presque toujours causée par un traumatisme majeur et est le plus souvent associée à des accidents de la route. Nous présentons un cas de rupture du diaphragme retardée chez une femme âgée de 35 , onze jours après un traumatisme fermé apparemment mineur. Ce cas illustre comment il est possible de manquer un diagnostic de rupture du diaphragme et démontre l'importance de considérer ce diagnostic dans tous les cas de traumatisme fermé au niveau du tronc. Il démontre également le risque potentiel d'une interprétation fautive des radiographies pulmonaires et l'utilité de répéter les épreuves d'imagerie après l'insertion d'une sonde nasogastrique.
\end{abstract}

\section{Background}

Injuries of the diaphragm were first described in 1541 by Sennertus. The first successful repair was performed by Riolfi in 1886. ${ }^{1}$ Rupture of the diaphragm due to blunt trauma is no longer uncommon, and its incidence has steadily in- creased with the rising number of road-traffic accidents. ${ }^{2}$ It is now reported to occur in $4 \%$ of multiple-injury cases, ${ }^{3}$ but it is extremely rare after minor trauma. We present an unusual case of delayed presentation of a patient with rupture of the diaphragm, complicated by gastric incarceration and perforation, after apparently minor blunt trauma.

From the Department of General Surgery, Changi General Hospital, Singapore

Received: Oct. 6, 2003; final submission: Jan. 15, 2004; accepted: Jan. 20, 2004

This article has been peer reviewed.

Can J Emerg Med 2004;6(4):277-80 


\section{Case report}

During a game of musical chairs at her office party, a 35year-old woman was accidentally kicked in her left flank and lower chest by a drunk and over-zealous colleague. The injury seemed minor, so she drove home and continued her usual daily activities over the next few days. However, 11 days later she developed cough, fever and sore throat, which were diagnosed as "influenza" by her family physician. Three days later, she developed sudden onset of vomiting and epigastric pain that radiated to the tip of her left shoulder. The pain did not resolve over the next 3 days, and she was referred by her family physician to the emergency department (ED).

On arrival, the patient was alert but dyspneic, with a respiratory rate of 33 breaths/min and an oxygen saturation of $95 \%$. She was hemodynamically stable but febrile, with a temperature of $39^{\circ} \mathrm{C}$. Auscultation revealed decreased air entry in the left chest and mild epigastric tenderness. The initial chest radiograph performed in the ED was interpreted as showing a loculated left pneumothorax (Fig. 1), and she was admitted to the respiratory unit. Fortunately, before tube thoracostomy, an astute respiratory physician inserted a nasogastric tube and repeated the

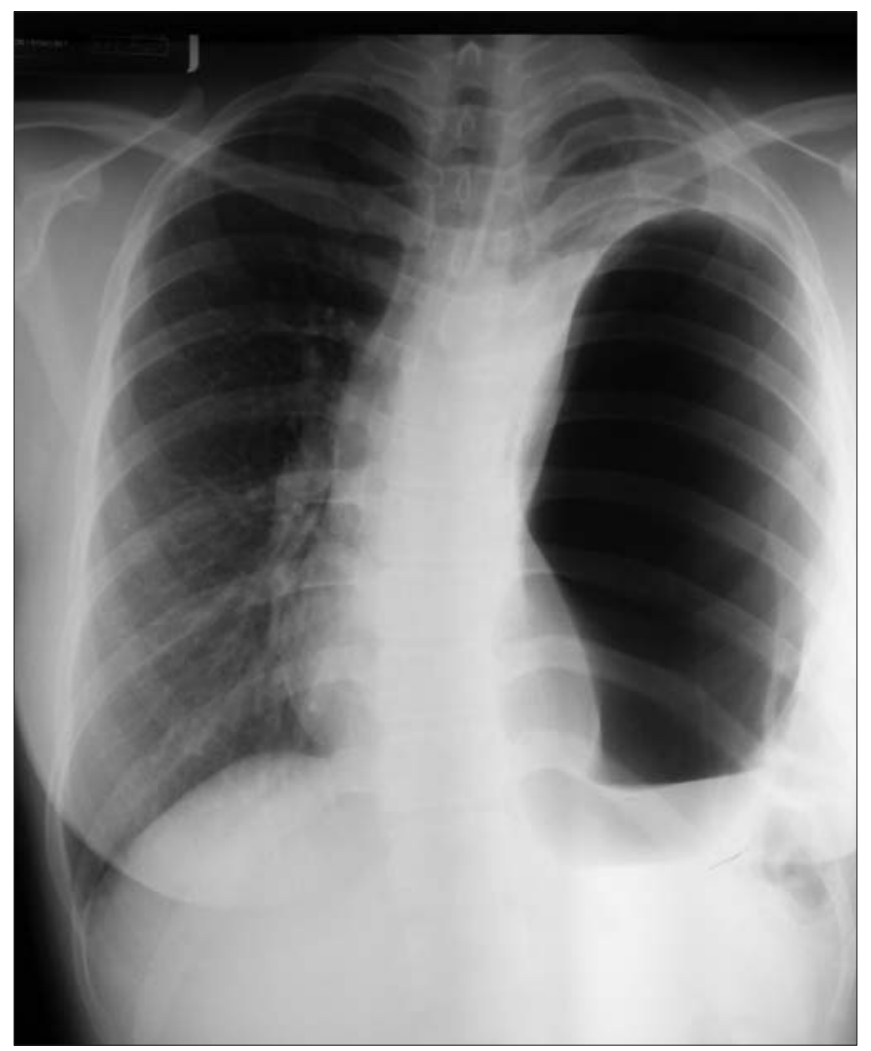

Fig. 1. First chest radiograph, results of which were interpreted as a loculated left pneumothorax. chest x-ray. This repeat view demonstrated left diaphragmatic rupture with herniation of viscus into the left hemithorax (Fig. 2).

She was referred to the surgical team, and an emergency celiotomy was performed. Operative findings revealed a $10-\mathrm{cm}$ defect in the posterolateral left hemi-diaphragm, with herniation of the stomach, greater omentum and the splenic flexure of the colon into the left chest. In addition, a capsular tear of the lower pole of the spleen was noted. The abdominal contents were reduced without difficulty, and a $5-\mathrm{cm}$ diameter necrotic perforation on the anterior wall of the body of the stomach was found. The diaphragm was repaired, and a Polya partial gastrectomy was performed because the necrotic gastric perforation was too large to close primarily. The injury to the spleen was managed conservatively. Her postoperative recovery was uneventful, and she was well on follow-up.

\section{Discussion}

Rupture of the diaphragm after blunt trauma is relatively uncommon, occurring in approximately $0.8 \%-1.6 \%$ of patients who are hospitalized with blunt trauma. ${ }^{4}$ It usually occurs in patients involved in major road-traffic acci-

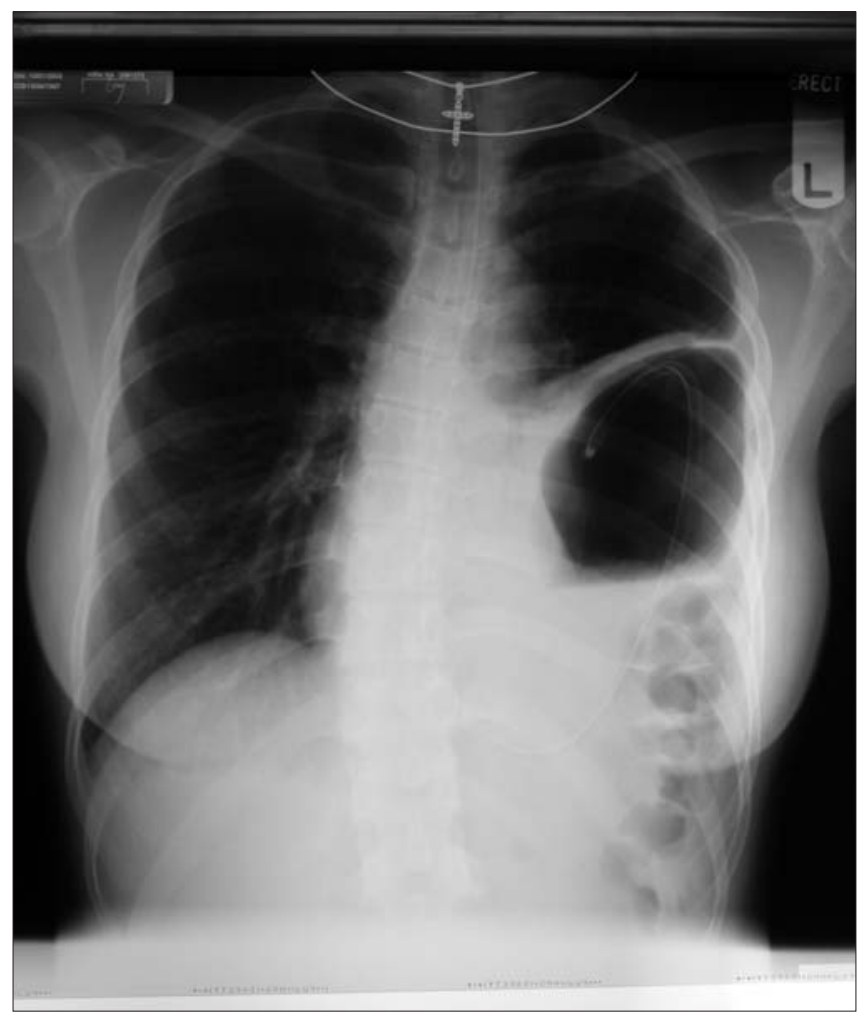

Fig. 2. Chest radiograph after nasogastric tube insertion clearly showing left diaphragmatic rupture with gastric herniation. 
dents and less frequently after falls from a height. These patients usually have severe multisystem injuries because of the large force required to rupture the diaphragm. ${ }^{1}$ Delayed presentation of a patient with a ruptured diaphragm after apparent minor blunt trauma that did not cause the patient to seek medical attention has not been previously reported.

Delayed presentation of ruptured diaphragm can be explained by 2 hypotheses: delayed rupture or delayed detection. ${ }^{5}$ Delayed rupture may occur when diaphragmatic muscle is devitalized during the initial injury but remains a tenuous barrier until several days later when the inflammatory process weakens it. Delayed detection, the more likely explanation, assumes that a diaphragmatic defect created at the time of the injury becomes clinically evident only when herniation occurs. ${ }^{1}$ Grimes first described the 3 phases of rupture of the diaphragm in $1974 .{ }^{6}$ The first (acute) phase begins at the time of the injury to the diaphragm. The second (delayed) phase is usually asymptomatic and may be associated with gradual herniation of abdominal contents into the chest. This phase may occur over months or years until complications arise. The third (obstructive) phase is characterized by bowel or visceral herniation, obstruction, incarceration, strangulation and possible rupture.

Previous reports suggested that $88 \%-95 \%$ of ruptures of the diaphragm caused by blunt trauma occurred on the left side, presumably because of the protection provided by the liver as well as underdiagnosis of right-sided injuries. However, autopsy studies have revealed that left- and rightsided ruptures occur almost equally. It is likely that the right-sided ruptures are recognized less often because they are associated with greater prehospital mortality, and because viscus herniation is less likely on the right side. More recent reports have revealed an increasing relative frequency of right-sided (20\%-50\%) and bilateral ruptures. $^{7-9}$ This probably reflects greater awareness of these injuries and improved trauma care, which enables more severely injured patients to survive to diagnosis.

The diagnosis of rupture of the diaphragm is difficult, and from $12 \%-69 \%$ of injuries are missed in the preoperative phase. ${ }^{8,10,11}$ Chest radiography is the primary diagnostic modality, and repeated imaging may increase diagnostic sensitivity, particularly in left-sided injuries. In a retrospective review of 44 patients with left-sided rupture of the diaphragm, initial chest radiographs were 52\% sensitive, but sensitivity increased to $64 \%$ when the $\mathrm{x}$-rays were repeated. ${ }^{12}$ Radiographic features include air-filled viscera in the thorax (45\% sensitive), obscured or discontinuous diaphragm contour (39\% sensitive) and "very elevated" hemi-diaphragm ( $61 \%$ sensitive). ${ }^{12}$ The most specific radiographic sign is the presence of air-containing viscera in the thorax, ${ }^{12}$ as seen in our patient. Repeat imaging after insertion of a nasogastric tube increases diagnostic sensitivity for left-sided injuries to approximately $75 \% .^{13}$ This was demonstrated in our patient, whose initial chest radiograph was mistaken for a pneumothorax. Fortunately, this misinterpretation did not lead to chest tube placement.

CT scanning is unreliable in cases of ruptured diaphragm; $;{ }^{8,14}$ consequently, several other techniques have been proposed, including thoracoscopy, laparoscopy, magnetic resonance imaging, ultrasonic or fluoroscopic evaluation of diaphragmatic motion, liver and lung scintiscanning, and intraperitoneal installation of radioisotope..$^{8,14}$ Experience with these modalities has been limited to small series or isolated case reports, and many are only feasible in stable patients.

Early recognition of a ruptured diaphragm is critical, because delayed diagnosis is associated with adverse outcome. In cases where herniation occurs, complicated by strangulation and gangrene, morbidity and mortality may reach $66 \%-80 \% .^{15,16}$ The clinical features of late-presenting hernia of the diaphragm are nonspecific and include abdominal pain, nausea, vomiting, dysphagia, chest pain and dyspnea. ${ }^{8}{ }^{8} 14$ Thus, emergency physicians should consider the diagnosis of ruptured diaphragm in patients with a history of blunt torso trauma who develop gastrointestinal or respiratory symptoms. In the case described above, delayed diagnosis occurred because the patient experienced relatively minor symptoms that were misdiagnosed as "influenza." Later, the sudden epigastric and lower chest pain were likely the result of acute strangulation and perforation of the stomach.

\section{Conclusion}

Although usually associated with major multisystem trauma, rupture of the diaphragm may occur after seemingly innocuous injury. Physicians should consider the diagnosis in patients who have a history of blunt trauma to the chest or abdomen and develop gastrointestinal or respiratory symptoms. The chest x-ray, especially when performed after insertion of a nasogastric tube, is a useful screening tool. Diaphragmatic irregularities or any evidence of gas above the diaphragm (in this case misinterpreted as an atypical "loculated pneumothorax") suggest the need to exclude gastric herniation due to ruptured diaphragm. In such cases, early diagnosis and intervention is important because delay in treatment will result in increased morbidity. 
Competing interests: None declared.

\section{References}

1. Meyers BF, McCabe CJ. Traumatic diaphragmatic hernia. Ann Surg 1993;218:783-90.

2. Cupitt JM, Smith MB. Missed diaphragm rupture following blunt trauma. Anaesth Intensive Care 2001;29:292-6.

3. Rodkey GV. The management of abdominal injuries. Surg Clin N Am 1966;46:627-44.

4. Shah R, Sabanathan S, Mearns AJ, Choudhury AK. Traumatic rupture of the diaphragm. Ann Thorac Surg 1995;60:1444-9.

5. Johnson CD. Blunt injuries of the diaphragm. Br J Surg 1988;7:226-30.

6. Grimes OF. Traumatic injuries of the diaphragm. Diaphragmatic hernia. Am J Surg 1974;128(2):175-81.

7. Boulanger BR, Milzman DP, Rosati C, Rodriguez A. A comparison of right and left blunt traumatic diaphragmatic rupture. J Trauma 1993;35:255-60.

8. Guth AA, Pachter HL, Kim U. Pitfalls in the diagnosis of blunt diaphragmatic injury. Am J Surg 1995;170:5-9.

9. McElwee TB, Myers RT, Pennell TC. Diaphragmatic rupture from blunt trauma. Am Surg 1984;50:143.
10. Wise L, Connors J, Hwang YH, Anderson C. Traumatic injuries to the diaphragm. J Trauma 1973;13:946-50.

11. Beal SL, McKennan M. Blunt diaphragm rupture: a morbid injury. Arch Surg 1988;123:828-32.

12. Gelman R, Mirvis SE, Gens D. Diaphragmatic rupture due to blunt trauma: sensitivity of plain chest radiographs. AJR 1991;156:51-7.

13. Perlman SJ, Rogers LF, Mintzer RA, Mueller CP. Abnormal course of nasogastric tube in traumatic rupture of left hemidiaphragm. AJR 1984;142:85-8.

14. Reber PU, Schmied B, Seiler HU, Patel AG, Buchler MW. Missed diaphragmatic injuries and their long-term sequelae. J Trauma 1998;44:183-8.

15. Hegarty MM, Bryer JV, Angorn IB, Baker LW. Delayed presentation of traumatic diaphragmatic hernia. Ann Surg 1978;188:229-33.

16. Christiansen LA, Blichert-Toft M, Bertelsen S. Strangulated diaphragmatic hernia: a clinical study. Am J Surg 1975;129:574-8.

Correspondence to: Dr. Brian K.P. Goh, Department of General Surgery, Changi General Hospital, 2, Simei St. 3, Singapore 520880; fax $+65-$ 67880933,bsgkp@hotmail.com 